\title{
Effects of Phendimetrazine Treatment on Cocaine vs Food Choice and Extended-Access Cocaine Consumption in Rhesus Monkeys
}

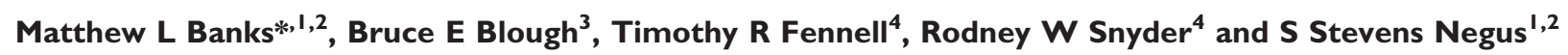 \\ 'Department of Pharmacology and Toxicology, Virginia Commonwealth University, Richmond, VA, USA; ${ }^{2}$ Institute for Drug and Alcohol Studies, \\ Virginia Commonwealth University, Richmond, VA, USA; ${ }^{3}$ Center for Organic and Medicinal Chemistry, Research Triangle Institute International, \\ Research Triangle Park, NC, USA; ${ }^{4}$ Department of Pharmacology and Toxicology, Research Triangle Institute International, Research Triangle \\ Park, NC, USA
}

\begin{abstract}
There is currently no Food and Drug Administration-approved pharmacotherapy for cocaine addiction. Monoamine releasers such as $\mathrm{d}$-amphetamine constitute one class of candidate medications, but clinical use and acceptance are hindered by their own high-abuse liability. Phendimetrazine (PDM) is a schedule III anorectic agent that functions as both a low-potency monoamine-uptake inhibitor and as a prodrug for the monoamine-releaser phenmetrazine (PM), and it may serve as a clinically available, effective, and safer alternative to $d$-amphetamine. This study determined efficacy of chronic PDM to reduce cocaine self-administration by rhesus monkeys $(N=4)$ using a novel procedure that featured both daily assessments of cocaine vs food choice (to assess medication efficacy to reallocate behavior away from cocaine choice and toward choice of an alternative reinforcer) and $20 \mathrm{~h} /$ day cocaine access (to allow high-cocaine intake). Continuous 21 -day treatment with ramping PDM doses (days I-7: $0.32 \mathrm{mg} / \mathrm{kg} / \mathrm{h}$; days $8-21: 1.0 \mathrm{mg} / \mathrm{kg} / \mathrm{h}$ ) reduced cocaine choices, increased food choices, and nearly eliminated extended-access cocaine self-administration without affecting body weight. There was a trend for plasma PDM and PM levels to correlate with efficacy to decrease cocaine choice such that the monkey with the highest plasma PDM and PM levels also demonstrated the greatest reductions in cocaine choice. These results support further consideration of PDM as a candidate anti-cocaine addiction pharmacotherapy. Moreover, PDM may represent a novel pharmacotherapeutic approach for cocaine addiction because it may simultaneously function as both a monoamine-uptake inhibitor (via the parent drug PDM) and as a monoamine releaser (via the active metabolite PM). Neuropsychopharmacology (20 I3) 38, 2698-2707; doi:I0.1038/npp.20 I3.180; published online 2I August 2013
\end{abstract}

Keywords: cocaine; choice; phendimetrazine; rhesus monkey; medication development; prodrug

\section{INTRODUCTION}

Cocaine addiction is a significant worldwide public health concern. In 2011, there were approximately 670000 persons aged 12 years or older who used cocaine for the first time within the past year in the United States alone, and this number of new users has remained stable since 2008 (SAMHSA, 2012). Furthermore, approximately $13 \%$ of admissions into a substance abuse treatment program in the United States have cocaine designated as the primary abused substance, and these admission statistics have remained stable since 1997 (SAMHSA, 2009). Although our understanding of the neurobiological mechanisms of cocaine addiction has dramatically improved over the last decade (Kalivas and Volkow, 2005), there is currently no

*Correspondence: Dr ML Banks, Department of Pharmacology and Toxicology, Virginia Commonwealth University, 410 North I 2th Street, PO Box 980613, Richmond, VA 23298, USA, Tel: + I 8048288466 , Fax: + 804828 2117, E-mail: mbanks7@vcu.edu

Received 15 April 2013; revised 23 July 2013; accepted 24 July 20।3; accepted article preview online 30 July 2013 approved Food and Drug Administration pharmacotherapy for cocaine addiction. Thus, there is a clear need for treatment strategies to address the public health problem of cocaine addiction.

Monoamine releasers such as $d$-amphetamine constitute one class of compounds being considered as candidate medications for treatment of cocaine addiction. Specifically, chronic $d$-amphetamine maintenance first demonstrated efficacy to decrease cocaine use in clinical trials (Grabowski et al, 2001; Mariani et al, 2012). Over the last decade, human laboratory studies (Greenwald et al, 2010; Rush et al, 2010) and preclinical studies in both nonhuman primates (Banks et al, 2013b; Negus, 2003) and rats (Thomsen et al, 2013) reported that chronic $d$-amphetamine treatment decreased cocaine self-administration in procedures that assessed choice between cocaine and a non-drug alternative (money in humans, food in rhesus monkeys and rats). Although concerns regarding the high-abuse liability of $d$-amphetamine and its corresponding schedule II controlled-substance status have hindered broad clinical acceptance, these clinical, human laboratory, and preclinical studies have provided a translational foundation for the development of 
other monoamine releasers as candidate medications for treating cocaine addiction. One compound to emerge from this translational drug development process is the clinically available anorectic agent phendimetrazine (PDM). PDM is a low-potency monoamine-uptake inhibitor and a prodrug for the monoamine-releaser phenmetrazine (PM) (Banks et al, 2013a; Rothman et al, 2002). We have previously shown that continuous 7-day treatment with PM produces an amphetamine-like decrease in cocaine self-administration in rhesus monkeys under limited, $1-2 \mathrm{~h}$, cocaine access conditions (Banks et al, 2011; Banks et al, 2013c; Negus et al, 2009); however, also like $d$-amphetamine, PM reliably maintains drug self-administration, and it is a schedule II controlled substance (Chait et al, 1987; Corwin et al, 1987; Rothman et al, 2002). By contrast, the prodrug PDM functioned as a reinforcer in one out of two drug selfadministration studies (Corwin et al, 1987; Griffiths et al, 1979), and this evidence for its lower abuse liability has contributed to its lower, schedule III, controlled-substance classification.

The aim of the present study was to investigate efficacy of chronic PDM to decrease cocaine self-administration by rhesus monkeys responding under a novel procedure that featured two major daily components (Figure 1a). First, intravenous cocaine injections were available during a daily 2-h choice session, during which subjects could choose between food pellets and various cocaine doses $(0-0.1 \mathrm{mg} / \mathrm{kg} /$ injection). A choice procedure was utilized because drug addiction has been conceptualized as a choice disorder (Ahmed, 2010; Banks and Negus, 2012; Hernstein and Prelec, 1992; Heyman, 2009), and a major goal of treating cocaine addiction is not only to decrease cocaine-taking behavior but also to increase behaviors maintained by alternative, nondrug reinforcers (Banks and Negus, 2012; Vocci, 2007; Volkow et al, 2004). Moreover, choice procedures provide rate-independent measures of medication effects on reinforcing efficacy of the self-administered drug (Augier et al, 2012; Banks et al, 2011; Czoty and Nader, 2013; Thomsen et al, 2013; Thomsen et al, 2008), and use of choice procedures in laboratory animal studies may also facilitate translation of results to human laboratory studies that also rely on choice procedures (Haney and Spealman, 2008). Second, cocaine injections $(0.1 \mathrm{mg} / \mathrm{kg} /$ injection) were available an additional $20 \mathrm{~h} /$ day under a fixed-ratio (FR) schedule to provide 'extended access' to cocaine and allow high daily rates of cocaine intake comparable to those observed in patients eligible for pharmacotherapy and most responsive to treatment with amphetamine-based medications (Mariani et al, 2012). We hypothesized that PDM treatment would decrease cocaine self-administration under both the choice and extended-access components of the daily schedule, consistent with the predicted profile of behavioral effects of an effective candidate medication.

\section{MATERIALS AND METHODS}

\section{Animals}

Four adult male rhesus monkeys (Macaca mulatta) were surgically implanted with a double-lumen catheter (Reiss Manufacturing, Blackstone, VA) inserted into a major vein (femoral or jugular) as previously described (Banks et al,

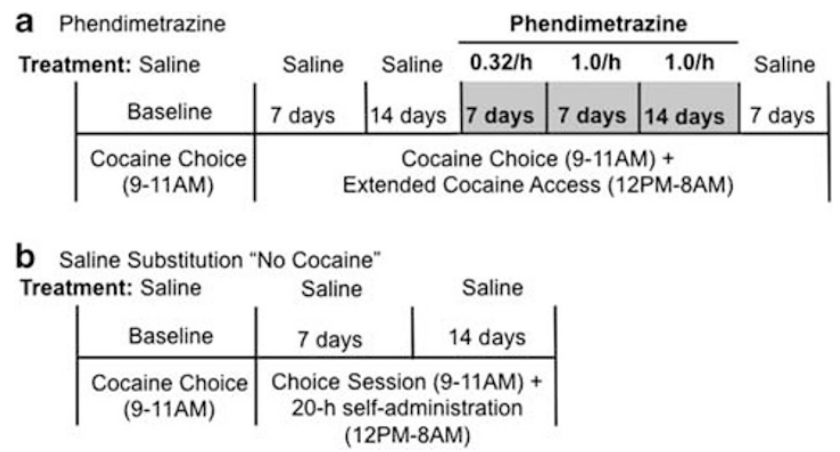

Figure I Experimental procedure. (a) Following a baseline period during which cocaine self-administration was only available during daily $2 \mathrm{~h}$ cocaine -vs food choice sessions, monkeys were subsequently given daily access to cocaine during both choice sessions and 'extended access' sessions lasting $20 \mathrm{~h}$ (noon to 0800 hours). During extended-access sessions, monkeys could respond for $0.1 \mathrm{mg} / \mathrm{kg} /$ injection cocaine under a FR $10 /$ time out 15-min schedule of reinforcement. After 14 days of extended cocaine access, $0.32 \mathrm{mg} / \mathrm{kg} / \mathrm{h}$ phendimetrazine (PDM) was continuously infused for 7 days, and then the PDM dose was increased to $1.0 \mathrm{mg} / \mathrm{kg} / \mathrm{h}$ PDM for 14 days for a total of 21 consecutive days of PDM treatment. Extended-access conditions were continued for an additional 7 days following PDM treatment. (b) Following 'baseline' cocaine vs food choice, saline was substituted for cocaine for a period of 14 days during both the choice session and $20 \mathrm{~h}$ self-administration conditions 'no cocaine.' All cocaineassociated stimuli, including intravenous injections, were retained.

2011). Monkeys weighed between 8 and $13 \mathrm{~kg}$ and were maintained on a diet of fresh fruit and food biscuits (Lab Diet High Protein Monkey Biscuits no. 5045; PMI Nutrition, St Louis, MO) provided in the afternoon after the choice session. Water was continuously available in the housing cage. A 12-h light-dark cycle was in effect (lights on from 0600 to 1800 hours). All monkeys had prior cocaine selfadministration histories (Banks et al, 2013b; Banks et al, 2013c). Animal research and maintenance were conducted according to the 8th edition of the Guide for the Care and Use of Laboratory Animals as adopted and promulgated by the National Institutes of Health. Animal facilities were licensed by the United States Department of Agriculture and accredited by the Association for Assessment and Accreditation of Laboratory Animal Care. The Institutional Animal Care and Use Committee approved the research protocol. Moreover, monkeys had visual, auditory, and olfactory contact with other monkeys throughout the study. Operant procedures and foraging toys were provided for environmental manipulation and enrichment. Videos were also played daily in animal housing rooms to provide additional environmental enrichment.

\section{Apparatus}

The home cage served as the experimental chamber as described previously (Banks et al, 2011; Banks and Negus, 2010; Negus, 2003). Briefly, each chamber was equipped with a custom operant panel, a pellet dispenser (Model ENV-203-1000; Med Associates, St Albans, VT), and two syringe pumps (Model PHM-108; Med Associates). One 'self-administration' pump delivered contingent cocaine or saline injections through one lumen of the catheter. The second 'treatment' pump delivered saline or a PDM dose through the second lumen of the catheter at a programmed 
rate of $0.1 \mathrm{ml}$ infusions every $20 \mathrm{~min}$ from 1200 hours each day until 1100 hours the next morning. The intravenous catheter was protected by a tether and jacket system (Lomir Biomedical, Malone, NY) that permitted monkeys to move freely.

\section{Behavioral Procedures}

Initially, monkeys responded under a concurrent schedule of food (1-g banana-flavored pellets; Test Diets, Richmond, IN) and intravenous cocaine ( $0-0.1 \mathrm{mg} / \mathrm{kg} /$ injection) availability as described in detail previously (Banks et al, 2011; Banks and Negus, 2010; Negus, 2003; Negus, 2004; Negus, 2005; Negus and Mello, 2004). Choice sessions were implemented daily from 0900 to 1100 hours and consisted of five 20-min components, with a different unit-cocaine dose available during each successive component $(0,0.0032$, $0.01,0.032$, and $0.1 \mathrm{mg} / \mathrm{kg} /$ injection during components $1-5$, respectively). Components were separated by 5 -min timeout periods. Manipulating the injection volume controlled the cocaine dose $(0,0.01,0.03,0.1$, and $0.3 \mathrm{ml} /$ injection, respectively). During each component, the left, foodassociated key was transilluminated red, and completion of the FR requirement (FR100) resulted in 1-g food pellet delivery. The right, cocaine-associated key was transilluminated green, and completion of the FR requirement (FR 10) resulted in delivery of the intravenous cocaine dose available during that component. Stimulus lights for the cocaine-associated key were flashed on and off in $3 \mathrm{~s}$ cycles, and longer flashes were associated with higher cocaine doses. Monkeys could complete up to a total of 10 ratio requirements on both the food- and cocaine-associated keys. Responding on either key reset the ratio requirement on the other key. Completion of each ratio requirement initiated a 3-s timeout, during which all stimulus lights were turned off, and responding had no programmed consequences. Choice behavior was considered stable when the lowest unit-cocaine dose maintaining at least $80 \%$ cocaine $v s$ food choice varied by $\leqslant 0.5 \log$ units for 3 consecutive days. Experimental parameters (unit-cocaine dose and dose order, alternative food reinforcer magnitude, and ratio requirement on food- and cocaine-associated keys) of the choice session used in this study were based on extensive parametric manipulations reported previously (Negus, 2003) and are identical to parameters used to assess other candidate medications effects on cocaine choice (Banks et al, 2011, 2013b; Banks et al, 2013c; Negus, 2004; Negus and Mello, 2004). Consequently, with the parameters used in this study, we could detect both leftward and rightward shifts in the cocaine $v s$ food choice dose-effect function that might result from manipulation of experimental variables.

When response allocation was stable, a multiple schedule of reinforcement was initiated to allow monkeys the opportunity to self-administer $0.1 \mathrm{mg} / \mathrm{kg} /$ injection cocaine under an FR 10 (15 min timeout) schedule of reinforcement for $20 \mathrm{~h}$ (1200 to 0800 hours) in addition to the choice session (Figure 1a). These parameters of 'extended cocaine access' were chosen based on our previous results (Banks and Negus, 2010). During extended cocaine access, only the cocaine-associated key was transilluminated green to signal cocaine availability. Completion of the response requirement extinguished the green light, activated the self-administration pump to deliver $0.1 \mathrm{mg} / \mathrm{kg} /$ injection cocaine, and initiated a 15-min timeout where responding had no programmed consequences and responses were not recorded. This multiple 'cocaine $v s$ food choice: extended cocaine access' schedule was implemented for a period of 14 consecutive days before continuous PDM treatment was initiated.

Initially, $0.32 \mathrm{mg} / \mathrm{kg} / \mathrm{h}$ PDM was continuously infused through the treatment lumen for 7 consecutive days. We chose this starting dose for two reasons. First, out of safety concerns because of the increased daily cocaine intake, we wanted to start with a low PDM dose that was inactive in a previous study (Banks et al, 2013b) before increasing the PDM dose. Second, we wanted to model aspects of clinical trials that use escalating dosing regimens for medication delivery (Grabowski et al, 2001; Grabowski et al, 2004). Subsequently, the PDM dose was increased to $1.0 \mathrm{mg} / \mathrm{kg} / \mathrm{h}$ for 14 consecutive days. Following termination of PDM treatment, extended cocaine access conditions were continued in addition to the cocaine $v s$ food choice session for an additional 7 days to assess recovery from PDM effects.

As an independent control experiment and for comparison with PDM effects, the availability of cocaine was removed, 'no cocaine', for 14 consecutive days to establish boundary conditions (Figure 1b). More specifically, this manipulation was designed to determine effects of the extreme case wherein reinforcing consequences associated with cocaine were eliminated. When cocaine $v s$ food choice was stable as described above without the extended cocaine access component 'baseline', the cocaine solution was replaced with saline in the self-administration pump for 14 consecutive days so that all other stimuli, including intravenous injections, were the same under both experiments. This multiple 'saline $v s$ food choice:20-h self-administration' schedule was implemented for a period of 14 consecutive days during which only saline was contingently available upon completion of the ratio requirement on the previous cocaine-associated key. At the end of the 14-day test period, the 20 -h self-administration component was terminated and cocaine availability was reinstated. This experiment was conducted after PDM experiments in all monkeys.

\section{Drugs}

( - )-Cocaine $\mathrm{HCl}$ was provided by the National Institute on Drug Abuse (Bethesda, MD) Drug Supply Program. (+)PDM fumarate was synthesized by BE Blough (RTI International, Research Triangle Park, NC). All drug doses are expressed as the salt forms listed above, and all drug solutions were passed through a sterile $0.2-\mu \mathrm{m}$ filter (EMD Millipore, Billerica, MA) before intravenous administration.

\section{PDM and PM Plasma Analysis Procedures}

After the choice session on the last day of PDM treatment, monkeys were anesthetized with ketamine $(10 \mathrm{mg} / \mathrm{kg}, \mathrm{IV})$, and 2-3 ml of blood was collected, immediately transferred to Vacutainer tubes containing K3-EDTA, and stored on ice until centrifugation at $1000 \mathrm{~g}$ for $10 \mathrm{~min}$. The plasma supernatant was pipetted into a labeled storage tube and frozen at $-80^{\circ} \mathrm{C}$. Frozen samples were shipped overnight 
on dry ice to RTI International for PM and PDM analysis, as previously described in detail (Banks et al, 2013a).

\section{Data Analysis}

The primary dependent measure for the choice session was percent cocaine choice, defined as (number of fixed ratios completed on the cocaine-associated key $\div$ total number of fixed ratios completed $)^{\star} 100$. The mean percent cocaine choice of the last 3 days of each experimental condition for each monkey was then plotted as a function of cocaine dose. Group mean cocaine choice dose-effect functions were analyzed using two-way repeated-measures (RMs) ANOVA with cocaine dose and experimental manipulation as the main factors. The primary dependent measure for the extended cocaine access session was the number of cocaine injections earned per $4-\mathrm{h}$ bin. These data were analyzed using a one-way RM ANOVA with experimental manipulation as the main factor. A significant ANOVA was followed by the Holm-Sidak multiple comparisons post-hoc test. The criterion for significance was set a priori at the $95 \%$ confidence level $(P<0.05)$. All analyses were conducted using Prism 6.0b for Mac (GraphPad Software, La Jolla, CA).

\section{RESULTS}

\section{Effects of Extended Cocaine Access on Cocaine Choice}

Monkeys initially responded under the cocaine vs food choice procedure in the absence of extended cocaine access, and these results are shown in Figure 2. Monkeys chose almost exclusively food when low-cocaine doses were available $(0-0.01 \mathrm{mg} / \mathrm{kg} /$ injection) and almost exclusively cocaine when high-cocaine doses were available (0.032$0.1 \mathrm{mg} / \mathrm{kg} /$ injection). Total daily cocaine intake averaged $1.2 \pm 0.0 \mathrm{mg} / \mathrm{kg}$. Introduction of extended-access cocaine increased daily cocaine intake to $7.8 \pm 0.7 \mathrm{mg} / \mathrm{kg}$, and monkeys responded for cocaine injections throughout the 20-h extended-access sessions (Figure 2b; Table 2). Figure 2a also shows that introduction of extended-access cocaine had little impact on cocaine $v s$ food choice during the daily choice sessions. At the end of both 7 and 14 days of extended cocaine access, choice of $0.032 \mathrm{mg} / \mathrm{kg} /$ injection cocaine was slightly but significantly decreased compared with conditions when cocaine was only available during the choice session (cocaine dose: $\mathrm{F}(4,12)=60.1, \quad P<0.05$; cocaine dose $\times$ extended access: $\mathrm{F}(8,24)=4.1, P<0.05)$. Extended cocaine access had no significant effect on the number of total, food, or cocaine choices earned. This profile of cocaine self-administration provided the behavioral baseline for analysis of PDM effects.

\section{Effects of PDM on Cocaine Self-Administration}

PDM-treatment effects on cocaine $v s$ food choice and extended cocaine access self-administration are shown in Figure 3. Continuous infusion of $0.32 \mathrm{mg} / \mathrm{kg} / \mathrm{h}$ PDM did not significantly alter cocaine $v s$ food choice. At the end of 7 treatment days with $1.0 \mathrm{mg} / \mathrm{kg} / \mathrm{h} \mathrm{PDM}$, choice of 0.032 $\mathrm{mg} / \mathrm{kg} /$ injection cocaine was significantly decreased (Figure 3a); at the end of 14 days, this PDM dose attenuated choice of both 0.032 and $0.1 \mathrm{mg} / \mathrm{kg} /$ injection cocaine
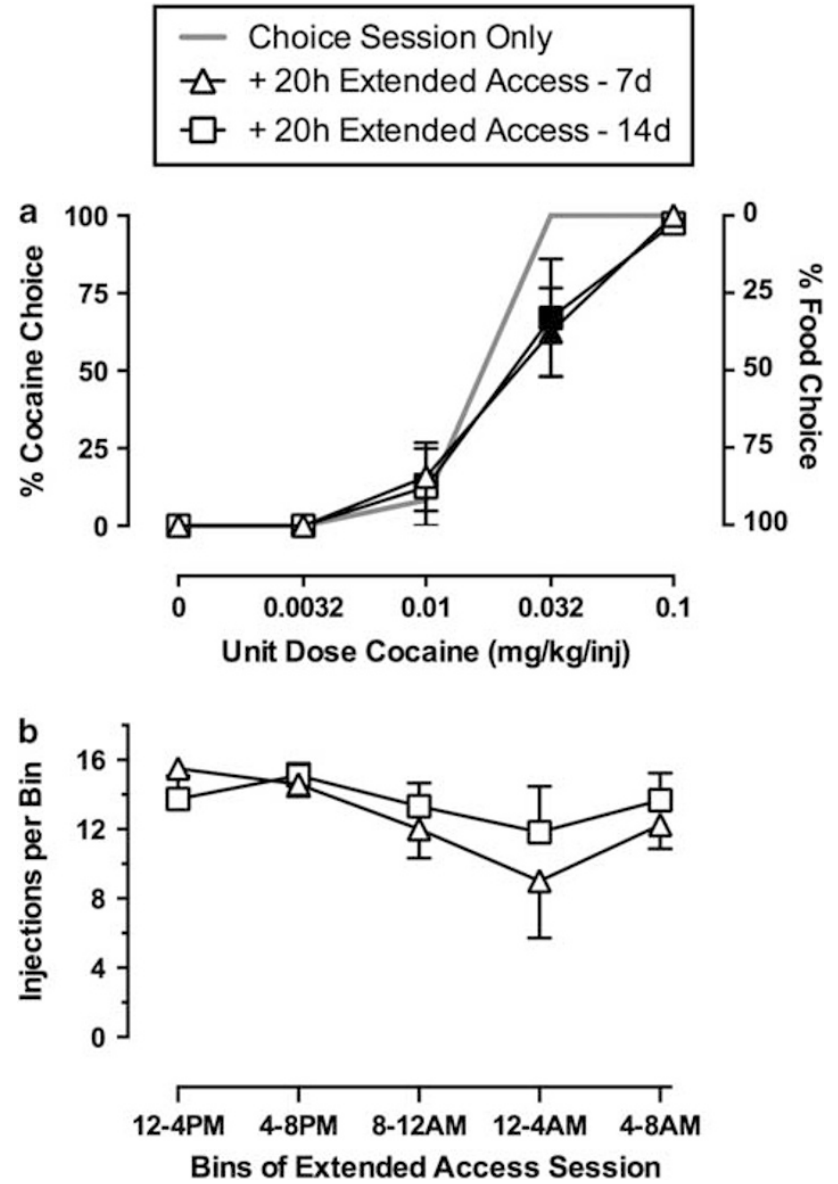

Figure 2 Effects of $20 \mathrm{~h}$ extended cocaine access on choice between cocaine and food in rhesus monkeys $(n=4)$. Top abscissae: unit dose cocaine in $\mathrm{mg} / \mathrm{kg} /$ injection. Top left ordinate: percent cocaine choice. Top right ordinate: percent food choice. Bottom abscissa: $4 \mathrm{~h}$ bins of the extended cocaine access session. Bottom ordinate: number of cocaine injections per each $4 \mathrm{~h}$ bin. All symbols represent mean $\pm \mathrm{SEM}$ of four monkeys from the last 3-day (days 5-7; 12-14) means of each experimental condition. Filled symbols indicate statistical significance $(P<0.05)$ compared with choice session only conditions.

(Figure 3a) (cocaine dose: $\mathrm{F}(4,12)=47.1, P<0.05$ ); PDM treatment: $\mathrm{F}(4,12)=4.4, \quad P<0.05$; cocaine dose $\times$ PDM treatment: $F(16,48)=2.9, P<0.05)$. For example, before PDM treatment, monkeys chose cocaine exclusively when $0.1 \mathrm{mg} / \mathrm{kg} /$ injection cocaine was available, and they earned approximately nine injections (Table 1). At the end of 14 treatment days with $1.0 \mathrm{mg} / \mathrm{kg} / \mathrm{h}$ PDM, monkeys earned approximately four injections of $0.1 \mathrm{mg} / \mathrm{kg} /$ injection cocaine, but also earned approximately four food pellets (Table 1). Figure $3 c$ shows that PDM treatment also decreased the number of cocaine injections earned per 4 -h bin of the extended cocaine access session (PDM treatment: $\mathrm{F}(3,9)=25.2, P<0.05)$. Treatment with $0.32 \mathrm{mg} / \mathrm{kg} / \mathrm{h} P D M$ significantly decreased the number of cocaine injections earned in all bins except for the 0000-0400-hour bin. Furthermore, $1.0 \mathrm{mg} / \mathrm{kg} / \mathrm{h}$ PDM treatment also significantly decreased the number of cocaine injections earned in all bins at both 7 and 14 treatment days. PDM also significantly $(\mathrm{F}(4,12)=24.0, \quad P<0.05)$ decreased total cocaine intake during treatment with $0.32 \mathrm{mg} / \mathrm{kg} / \mathrm{h} \mathrm{PDM}(5.3 \pm 1.2 \mathrm{mg} / \mathrm{kg})$ 


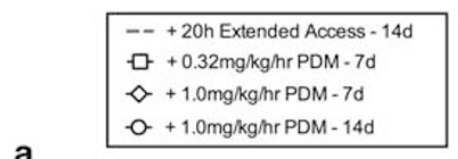

a
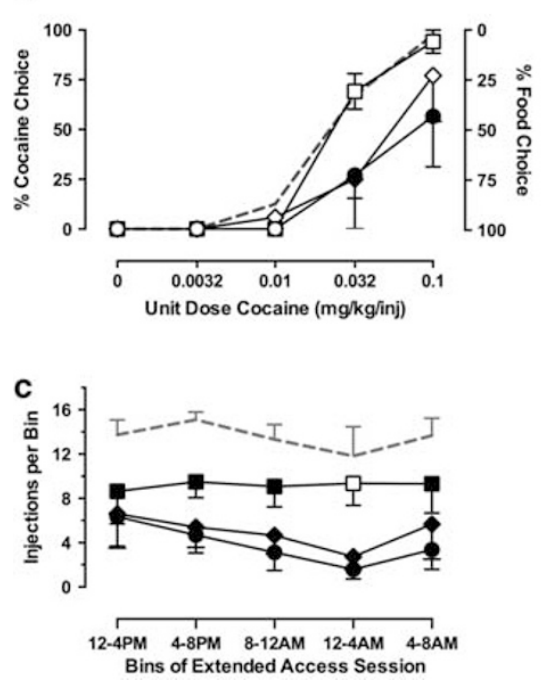
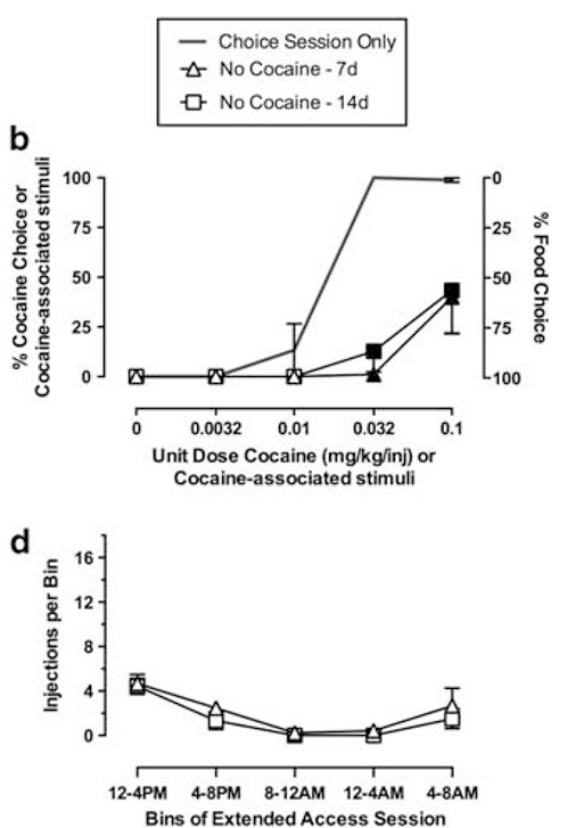

Figure 3 Effects of 2 I days of continuous ( + )-phendimetrazine (PDM) treatment on choice between cocaine and food and cocaine consumption during the 20-h extended cocaine access in rhesus monkeys $(n=4 ; a, c)$. For comparison, the effects of 14 days of substituting saline 'no cocaine' for cocaine in both the choice procedure and $20 \mathrm{~h}$ extended-access session in rhesus monkeys $(n=3 ; b, d)$. Top abscissae: unit dose cocaine in mg/kg/injection or cocaineassociated stimuli. Top left ordinates: percent cocaine choice. Top right ordinates: percent food choice. Bottom abscissa: $4 \mathrm{~h}$ bins of the extended cocaine access session. Bottom ordinates: number of cocaine injections per each $4 \mathrm{~h}$ bin. All symbols represent mean \pm SEM of four monkeys from the last 3-day (days 5-7; 12-14; 19-2I) means of each experimental condition. Filled symbols indicate statistical significance compared with ' $+20 \mathrm{~h}$ extended access- 14 days' conditions for a and $c$ and compared with 'choice session alone' for b.

and with $7(3.0 \pm 1.2 \mathrm{mg} / \mathrm{kg})$ and 14 days $(2.3 \pm 0.7 \mathrm{mg} / \mathrm{kg})$ of $1.0 \mathrm{mg} / \mathrm{kg} / \mathrm{h}$ PDM (see Table 2 for mean group results and Supplementary Table 1 for individual results of PDM treatment on cocaine intake).

Figure 4 shows recovery of both cocaine choice and extended-access cocaine self-administration following PDM treatment. One monkey lost catheter patency during the 7day post-PDM treatment, hence the group data are the mean of the mean of days 5-7 post-PDM from three monkeys. Cocaine choice (panel A) returned to pre-PDM treatment levels after 7 days, and extended-access cocaine self-administration (panel B) also approached pre-PDM treatment levels, although the number of injections earned was still significantly decreased during the 0800-0000- and 0000-0400-hour bins of the extended-access session. Supplementary Figure 1 shows total, food, and cocaine choices per session recovered to baseline levels at the end of 7 days post PDM treatment.

\section{Effects of Substituting Saline for Cocaine}

To provide a comparison with PDM treatment effects on cocaine self-administration, an independent control experiment was conducted by substituting saline 'no cocaine' for cocaine injections in both the cocaine $v s$ food choice procedure and the extended-access session for 14 days while retaining all cocaine-associated stimuli (Figures $3 b-d$ ). Saline substitution decreased the number of choices completed on the previous cocaine-associated key during components when stimuli associated with 0.032 and 0.1 $\mathrm{mg} / \mathrm{kg} /$ injection cocaine were presented and reciprocally increased the number of pellets earned on the foodassociated key (Table 1) (cocaine dose: $\mathrm{F}(4,8)=20.2$, $P<0.05$; saline substitution: $\mathrm{F}(2,4)=38.4, P<0.05$; cocaine dose $\times$ saline substitution: $F(8,16)=12.9, P<0.05)$. Saline substitution also decreased the number of injections earned per bin of the extended-access session (Figure 3d). The mean $( \pm$ SEM) number of saline injections earned during the entire extended-access session at the end of 14 days of saline substitution was $7.3( \pm 1.9)$ injections compared with $64.4( \pm 8.4)$ injections earned at the end of 14 days when $0.1 \mathrm{mg} / \mathrm{kg} /$ injection cocaine was available.

\section{Plasma PDM and PM Levels}

Supplementary Table 3 reports individual and group plasma PDM and PM levels. There was a trend for a correlation between plasma PDM and PM levels and reductions in cocaine self-administration during both the choice session and the 20-h extended cocaine access session. For example, the monkey (M1489) with the highest PDM $(620 \mathrm{ng} / \mathrm{ml})$ and PM (934 ng/ml) levels also demonstrated the largest PDM treatment effect in decreasing cocaine choice, whereas the monkey (M1504) with the lowest PDM (300 ng/ml) and PM $(541 \mathrm{ng} / \mathrm{ml})$ levels showed the smallest PDM effect.

\section{DISCUSSION}

This study determined effects of continuous PDM treatment on cocaine self-administration in rhesus monkeys using a novel procedure that featured both daily assessments of 
Table I Number of Cocaine Injections, Food Pellets, and Total Reinforcers Earned Per Component of the Cocaine vs Food Choice Session under the Different Experimental Conditions

\begin{tabular}{|c|c|c|c|c|c|}
\hline & $\mathrm{Cl}$ & C2 & C3 & C4 & C5 \\
\hline Choice session only & 0 & 0.0032 & 0.01 & 0.032 & 0.1 \\
\hline Cocaine injections & $0(0)$ & $0(0)$ & $0.8(0.8)$ & $10(0)$ & $8.8(0.2)$ \\
\hline Food pellets & $10(0)$ & $9.8(0.2)$ & $9.0(0.9)$ & $0(0)$ & $0(0)$ \\
\hline Total $S^{R}$ & $10(0)$ & $9.8(0.2)$ & $9.8(0.2)$ & $10(0)$ & $8.8(0.2)$ \\
\hline+ Extended access -7 days & 0 & 0.0032 & 0.01 & 0.032 & 0.1 \\
\hline Cocaine injections & $0(0)$ & $0(0)$ & $1.5(1.0)$ & $5.6(1.7)$ & $7.1(1.6)$ \\
\hline Food pellets & $9.6(0.4)$ & $9.2(0.5)$ & $7.5(1.1)$ & $3.1(1.4)$ & $0(0)$ \\
\hline Total $S^{R}$ & $9.6(0.4)$ & $9.2(0.5)$ & $9.0(0.8)$ & $8.7(1.3)$ & $7.1(1.6)$ \\
\hline+ Extended access-14 days & 0 & 0.0032 & 0.01 & 0.032 & 0.1 \\
\hline Cocaine injections & $0(0)$ & $0(0)$ & $0.8(0.8)$ & $6.4(2.1)$ & $8.3(1.1)$ \\
\hline Food pellets & $9.8(0.3)$ & $8.2(1.1)$ & $6.4(1.5)$ & $2.7(1.6)$ & $0.2(0.2)$ \\
\hline Total $S^{R}$ & $9.8(0.3)$ & $8.2(1.1)$ & $7.3(1.0)$ & $9.1(0.8)$ & $8.4(0.9)$ \\
\hline$+0.32 \mathrm{mg} / \mathrm{kg} / \mathrm{h}$ PDM -7 days & 0 & 0.0032 & 0.01 & 0.032 & 0.1 \\
\hline Cocaine injections & $0(0)$ & $0(0)$ & $0(0)$ & $5.9(1.4)$ & $6.1(1.0)$ \\
\hline Food pellets & $7.3(1.6)$ & $7.6(.4)$ & $7.7(1.4)$ & $2.6(1.0)$ & $0.3(0.3)$ \\
\hline Total $S^{R}$ & $7.3(1.6)$ & $7.6(1.4)$ & $7.7(1.4)$ & $8.4(1.6)$ & $6.4(0.8)$ \\
\hline$+1.0 \mathrm{mg} / \mathrm{kg} / \mathrm{hPDM}-7$ days & 0 & 0.0032 & 0.01 & 0.032 & 0.1 \\
\hline Cocaine injections & $0(0)$ & $0(0)$ & $0.4(0.4)$ & $2.5(2.5)$ & $3.9(1.7)$ \\
\hline Food pellets & $8.3(1.7)$ & $7.9(1.4)$ & $7.2(174)$ & $5.0(2.0)$ & $0.8(0.8)$ \\
\hline Total $S^{R}$ & $8.3(1.7)$ & $7.9(1.4)$ & $7.6(1.6)$ & $7.5(.4)$ & $4.7(1.3)$ \\
\hline$+1.0 \mathrm{mg} / \mathrm{kg} / \mathrm{h}$ PDM-14 days & 0 & 0.0032 & 0.01 & 0.032 & 0.1 \\
\hline Cocaine injections & $0(0)$ & $0(0)$ & $0(0)$ & $1.7(1.1)$ & $3.8(1.8)$ \\
\hline Food pellets & $7.9(0.9)$ & $5(2)$ & $7(1.4)$ & $4.1(1.7)$ & $3.9(2.2)$ \\
\hline Total $S^{R}$ & $7.9(0.9)$ & $5(2)$ & $7(1.4)$ & $5.8(1.7)$ & $7.6(1.4)$ \\
\hline Choice session only & 0 & 0.0032 & 0.01 & 0.032 & 0.1 \\
\hline Cocaine injections & $0.1(0.1)$ & $0(0)$ & $1.3(1.3)$ & $10(0)$ & $9.8(0.1)$ \\
\hline Food pellets & $9.9(0.1)$ & $9.7(0.3)$ & $8.7(1.3)$ & $0(0)$ & $0.1(0.1)$ \\
\hline Total $S^{R}$ & $10(0)$ & $9.7(0.3)$ & $10(0)$ & $10(0)$ & $9.9(0.1)$ \\
\hline No cocaine -7 days & 0 & 0 & 0 & 0 & 0 \\
\hline Injections & $0(0)$ & $0(0)$ & $0(0)$ & $0.1(0.1)$ & $4(1.8)$ \\
\hline Food pellets & $10(0)$ & $10(0)$ & $10(0)$ & $9.9(0.1)$ & $6(1.8)$ \\
\hline Total $S^{R}$ & $10(0)$ & $10(0)$ & $10(0)$ & $10(0)$ & $10(0)$ \\
\hline No cocaine_-14 days & 0 & 0 & 0 & 0 & 0 \\
\hline Injections & $0(0)$ & $0(0)$ & $0(0)$ & $1.2(1.1)$ & $4.3(2.2)$ \\
\hline Food pellets & $10(0)$ & $10(0)$ & $10(0)$ & $8.8(1.1)$ & $5.7(2.2)$ \\
\hline Total $S^{R}$ & $10(0)$ & $10(0)$ & $10(0)$ & $10(0)$ & $10(0)$ \\
\hline
\end{tabular}

The corresponding unit-cocaine dose available in each component of the choice procedure is shown in $\mathrm{mg} / \mathrm{kg} /$ injection. All data represent the group mean ( \pm SEM) of the last 3-day means for each monkey for each experimental condition.

The bold entries represent the unit cocaine dose that was available during each component of the choice session.

cocaine $v s$ food choice (to assess medication efficacy to reallocate behavior away from cocaine consumption and toward consumption of a competing, non-drug alternative) and $20 \mathrm{~h}$ per day extended cocaine access (to allow high daily cocaine intakes). The main result was that continuous PDM treatment decreased cocaine choice, produced a reciprocal increase in food choice, and decreased cocaine consumption during extended access. Overall, these results demonstrate the efficacy of PDM to decrease cocaine-taking behavior under multiple conditions and under periods of high-cocaine intake. This result supports further consideration of PDM as an anti-cocaine addiction medication.

\section{Utility of Choice Procedures in Medication Development}

Although preclinical choice procedures have been sparsely used in drug self-administration research since the 1940 s (Banks and Negus, 2012; Spragg, 1940), there has been a surge in use of these procedures within the past decade in both rodents (Cantin et al, 2010; Lenoir et al, 2007; Thomsen et al, 2008) and nonhuman primates (Banks et al, 2011; Czoty and Nader, 2013; Negus, 2003). We (Banks and Negus, 2012) and others (Ahmed, 2010; Haney and Spealman, 2008) have argued that choice procedures may contribute to preclinical research on medication development for drug addiction for at least three reasons. First, choice procedures focus on measures of allocation rather than rates of operant responding, and consequently, they provide a rate-independent measure of medication effects on reinforcing efficacy of the self-administered drug. In particular, candidate medications that promote a shift in choice away from drug and toward a non-drug alternative can be dissociated from candidate medications that decrease responding maintained by both drug and nondrug reinforcers without affecting choice. Second, human laboratory studies of candidate medications for addiction treatment increasingly rely on choice procedures, and preclinical use of choice procedures may improve preclinical-to-clinical translation of results (Banks and Negus, 2012; Haney and Spealman, 2008). Lastly, preclinical choice procedures provide one, albeit simplified, strategy for modeling the ultimate treatment goal of promoting reallocation of drug-taking behavior to other behaviors maintained by safer non-drug reinforcers.

\section{Effects of Extended Cocaine Access and Saline Substitution on Cocaine Choice}

Consistent with previous studies from our laboratory (Banks et al, 2011, 2013b; Negus, 2003) and others (Kerstetter et al, 2012; Nader and Woolverton, 1991; Thomsen et al, 2013; Thomsen et al, 2008), cocaine maintained a dose-dependent increase in choice over an alternative food reinforcer. Introducing conditions of extended cocaine access increased daily cocaine intakes more than sixfold and resulted in a small but significant rightward shift in the cocaine choice dose-effect function. This result is consistent with a previous results from our laboratory examining effects of extended cocaine access and subsequent withdrawal on cocaine $v s$ food choice (Banks and Negus, 2010). Although medication treatment could modify cocaine self-administration and cocaine choice by multiple mechanisms, one potential mechanism would be to block detection of self-administered cocaine, resulting in extinction of cocaine-maintained behaviors. To model this outcome and to provide a comparison for PDM-treatment effects, we evaluated effects of substituting saline for cocaine. As expected, eliminating cocaine delivery 
Table 2 Effects of 2 I-Day Continous Phendimetrazine Treatment on Group Mean $(N=4)$ Cocaine Intakes (mg/kg) During Both the Cocaine vs Food Choice Procedure and the 20-h Extended Cocaine Access Session in Rhesus Monkeys

\begin{tabular}{lccr}
\hline & Choice session cocaine $\mathbf{( m g / k g )}$ & Extended-access cocaine $(\mathbf{m g} / \mathbf{k g})$ & Total daily cocaine $(\mathbf{m g} / \mathbf{k g})$ \\
\hline Choice session only & $1.2(0.0)$ & - & $1.2(0.0)$ \\
+ Extended access-7 days & $0.9(0.2)$ & $6.3(0.7)$ & $7.2(0.7)$ \\
+ Extended access-14 days & $1.0(0.1)$ & $6.8(0.7)$ & $7.8(0.7)$ \\
$+0.32 \mathrm{mg} / \mathrm{kg} / \mathrm{h}$ PDM-7 days & $0.7(0.2)$ & $4.6(1.0)$ & $5.3(1.2)$ \\
$+1.0 \mathrm{mg} / \mathrm{kg} / \mathrm{hPDM}-7$ days & $0.5(0.2)$ & $2.5(1.0)$ & $3.0(1.2)$ \\
$+1.0 \mathrm{mg} / \mathrm{kg} / \mathrm{h}$ PDM-14 days & $0.4(0.2)$ & $1.9(0.6)$ & $2.3(0.7)$ \\
\hline
\end{tabular}

All data points represent group mean $( \pm$ SEM) cocaine intakes of the last 3 days means of each 7-day experimental condition for each individual monkey.
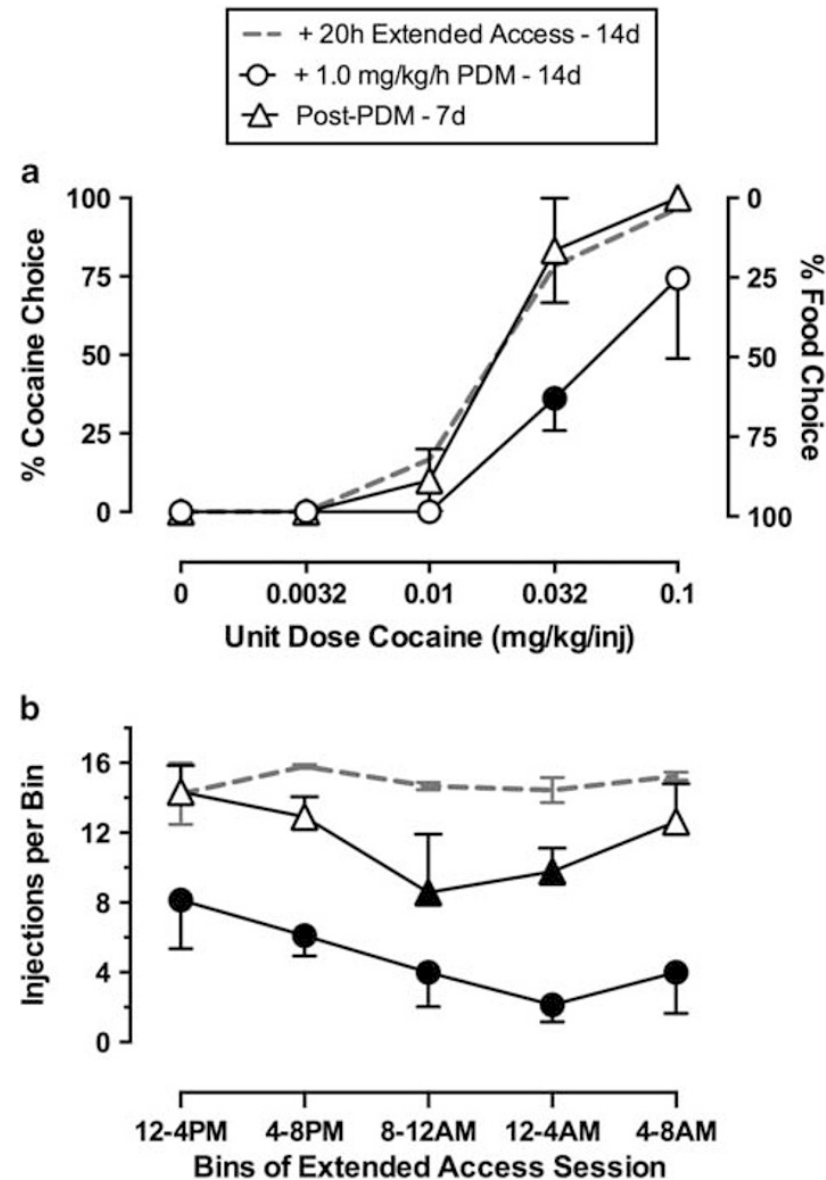

Figure 4 Recovery of cocaine vs food choice and cocaine consumption following termination of continuous $(+)$-phendimetrazine (PDM) treatment in rhesus monkeys ( $n=3)$. Top abscissae: unit dose cocaine in $\mathrm{mg} / \mathrm{kg} /$ injection. Top left ordinate: percent cocaine choice. Top right ordinate: percent food choice. Bottom abscissa: $4 \mathrm{~h}$ bins of the extended cocaine access session. Bottom ordinate: number of cocaine injections per each $4 \mathrm{~h}$ bin. All symbols represent mean \pm SEM of three monkeys from the last 3-day means of each experimental condition. The fourth monkey lost catheter patency during the 7-day post-PDM period, and his data are excluded for this figure. Filled symbols indicate statistical significance $(P<0.05)$ compared with ' $+20 \mathrm{~h}$ extended-access - 14 days' conditions.

decreased choice of cocaine-associated stimuli and produced a reciprocal increase in food choice similar to a previous study (Banks et al, 2011). Furthermore, eliminating cocaine delivery also significantly decreased the number of injections earned during the extended-access component. Overall, these results confirm the sensitivity of our procedure to experimental manipulations that have an impact on the consequences of behavioral allocation between the cocaine-associated and food-associated keys. Moreover, this saline substitution experiment provides an empirical framework for interpreting PDM effects.

\section{Effects of PDM on Cocaine Choice}

In the present study, PDM decreased cocaine-taking behavior during both the cocaine $v s$ food choice component and the extended cocaine access component of the daily procedure. Specifically, PDM produced a reallocation of behavior away from the cocaine-associated key to the foodassociated key during components when 0.032 or $0.1 \mathrm{mg} / \mathrm{kg} /$ injection cocaine was the alternative to food. Moreover, PDM reduced cocaine-maintained responding to a similar magnitude as substituting saline during the 20-h selfadministration component. Taken together, these PDMtreatment effects were qualitatively similar to effects of removing cocaine availability for 14 days, and this similarity suggests that PDM treatment reduced cocaine choice and extended-access cocaine self-administration at least in part by reducing the reinforcing efficacy of self-administered cocaine. However, there were also some differences in effects of PDM treatment and saline substitution. For example, unlike saline substitution, PDM decreased the number of food pellets earned when low-cocaine doses were available during choice components and subjects primarily chose food. Moreover, PDM treatment produced less reallocation to food choice than saline substitution. These findings suggest that, in addition to reducing sensitivity to cocaine reinforcement, PDM also produced non-selective effects on operant responding, and expression of such nonselective effects may limit the range of PDM doses that could be used clinically to treat cocaine addiction. However, two additional findings suggest that non-selective effects of PDM on food-maintained responding may be relatively modest. First, tolerance developed to effects of PDM on food-maintained responding over the course of chronic treatment in the present study, and longer treatment may have produced further tolerance. For example, we (Negus and Mello, 2003b) and others (Czoty et al, 2011) have previously demonstrated full recovery of amphetamineinduced reductions in food-maintained responding after 28 consecutive treatment days. Second, none of the subjects 
lost weight during the present study, suggesting that subjects continued to consume enough food from daily rations and earned enough pellets to maintain body weight.

The novel preclinical procedure employed in the present study was intended to model intensive 'heavy' cocaine use, and effects of PDM in this procedure extend the conditions under which monoamine releaser-based medications have decreased cocaine self-administration in nonhuman primate studies. For example, we have previously shown that dopamine-selective monoamine releasers, such as $d$-amphetamine and PM, are effective in decreasing cocaine choice under conditions that limit maximum daily cocaine intakes to approximately $1.2 \mathrm{mg} / \mathrm{kg} /$ day (Banks et al, 2011, 2013b; Banks et al, 2013c; Negus, 2003). Monoamine releaser-induced reductions in cocaine self-administration have also been demonstrated under other schedules of reinforcement associated with a broad range of daily cocaine intakes in both nonhuman primates (Czoty et al, 2010; Czoty et al, 2011; Negus and Mello, 2003a; Negus and Mello, 2003b) and rats (Chiodo and Roberts, 2009; Chiodo et al, 2008; Thomsen et al, 2013). These preclinical data from nonhuman primates and rats complement human data (Greenwald et al, 2010; Rush et al, 2010) that also demonstrate reductions in cocaine self-administration during chronic monoamine-releaser treatment. Taken together, dopamine-selective monoamine releasers have decreased cocaine self-administration across a broad range of experimental conditions in multiple species.

\section{Mechanisms of PDM-Induced Decreases in Cocaine Self-Administration}

General mechanisms that may underlie reductions in cocaine self-administration during maintenance on monoamine releasers have been discussed previously (Negus and Mello, 2003b). Briefly, a growing body of evidence suggests that monoamine-releaser maintenance may reduce sensitivity to the reinforcing effects of self-administered cocaine either (a) because the releaser, together with releaserinduced increases in extracellular levels of monoamine neurotransmitters, may compete with cocaine for binding sites on monoamine transporters and/or (b) because monoamine-releaser treatment may downregulate monoamine transporters or induce other adaptations to neural targets necessary for cocaine effects. Clarification of these general mechanisms will require further research, but in the context of the present study, the unique pharmacology of PDM warrants particular comment. PDM is unusual as a monoamine transporter ligand in that the parent drug functions as a low-potency uptake inhibitor, but the primary metabolite PM functions with approximately 10 -fold higher potency as a monoamine releaser (Rothman et al, 2002). Consequently, PDM effects reflect some synthesis of effects associated with monoamine-uptake inhibition produced by PDM and monoamine release produced by PM. For example, after acute intramuscular administration of a range of PDM doses in rhesus monkeys, peak PDM levels were observed soon after drug administration (Tmax of 10-20 min), whereas peak PM levels were approximately 10 -fold lower in magnitude and were not observed until much later after injection (Tmax of 2-3 h) (Banks et al, 2013a). Thus, acute PDM administration produced a sequence of effects dominated initially by monoamine-uptake blockade and later by monoamine release. The regimen of chronic PDM treatment in the present study produced PDM plasma levels similar to those produced by a low acute PDM dose; however, PM plasma levels were nearly double those of PDM plasma levels and much greater than peak PM plasma levels achieved after acute PDM treatment or after acute treatment with behaviorally active doses of PM itself (Banks et al, 2013a). These results suggest two conclusions. First, PM levels accumulated to a greater degree than PDM levels, and effects of chronic PDM administration would be expected to result more from monoamine release (by $\mathrm{PM}$ ) than from uptake inhibition (by PDM). Second, the presence of PDM appears to have permitted accumulation of high PM concentrations well above those produced by acute treatment with behaviorally active doses of either PDM or PM itself. Taken together, these results suggest the possibility that chronic PDM treatment may serve as a relatively safe and effective strategy for achieving and maintaining high and therapeutically effective plasma concentrations of a monoamine releaser.

\section{FUNDING AND DISCLOSURE}

Research reported in this publication was supported by the National Institute on Drug Abuse of the National Institutes of Health under Award Numbers R01DA026946 and R01DA012970. The content is solely the responsibility of the authors and does not necessarily represent the official views of the National Institutes of Health. Dr Banks declares that his research has been funded by NIH. During the past 3 years, he has received compensation as a collaborator with the pharmaceutical companies Abbott and Purdue for projects related to opioid pharmacology and analgesic drug development. Dr Banks declares that the present study was not related to this professional relationship and should not be perceived as constituting a potential conflict of interest. Dr Negus declares that his research has been funded by NIH. During the past 3 years, he has received compensation as a consultant for or collaborator with the pharmaceutical companies Abbott and Limerick Biopharma for projects related to opioid pharmacology, analgesic drug development, or assessment of abuse liability. Dr Negus declares that the present study was not related to this professional relationship and should not be perceived as constituting a potential conflict of interest. Dr Blough declares that his research has been funded by NIH. Dr Blough declares that his research has been funded by NIH. Dr Fennell and $\mathrm{Mr}$ Snyder declare no conflicts of interest.

\section{ACKNOWLEDGEMENTS}

We thank Jennifer Gough and Crystal Reyns for technical assistance and Kevin Costa for writing the computer program.

\section{REFERENCES}

Ahmed SH (2010). Validation crisis in animal models of drug addiction: beyond non-disordered drug use toward drug addiction. Neurosci Biobehav Rev 35: 172-184. 
Augier E, Vouillac C, Ahmed SH (2012). Diazepam promotes choice of abstinence in cocaine self-administering rats. Addiction Biol 17: 378-391.

Banks ML, Blough BE, Fennell TR, Snyder RW, Negus SS (2013a). Role of phenmetrazine as an active metabolite of phendimetrazine: evidence from studies of drug discrimination and pharmacokinetics in rhesus monkeys. Drug Alcohol Depend 130: $158-166$.

Banks ML, Blough BE, Negus SS (2011). Effects of monoamine releasers with varying selectivity for releasing dopamine/ norepinephrine versus serotonin on choice between cocaine and food in rhesus monkeys. Behav Pharmacol 22: 824-836.

Banks ML, Blough BE, Negus SS (2013b). Effects of 14-day treatment with the schedule III anorectic phendimetrazine on choice between cocaine and food in rhesus monkeys. Drug Alcohol Depend 131: 204-213.

Banks ML, Blough BE, Stevens Negus S (2013c). Interaction between behavioral and pharmacological treatment strategies to decrease cocaine choice in rhesus monkeys. Neuropsychopharmacology 38: 395-404.

Banks ML, Negus SS (2010). Effects of extended cocaine access and cocaine withdrawal on choice between cocaine and food in rhesus monkeys. Neuropsychopharmacology 35: 493-504.

Banks ML, Negus SS (2012). Preclinical determinants of drug choice under concurrent schedules of drug self-administration. Adv Pharmacological Sci 2012: 17.

Cantin L, Lenoir M, Augier E, Vanhille N, Dubreucq S, Serre F et al (2010). Cocaine is low on the value ladder of rats: possible evidence for resilience to addiction. PLoS ONE 5: e11592.

Chait LD, Uhlenhuth EH, Johanson CE (1987). Reinforcing and subjective effects of several anorectics in normal human volunteers. J Pharmacol Exp Ther 242: 777-783.

Chiodo K, Roberts DS (2009). Decreased reinforcing effects of cocaine following 2 weeks of continuous d-amphetamine treatment in rats. Psychopharmacology 206: 447-456.

Chiodo KA, Läck CM, Roberts DCS (2008). Cocaine self-administration reinforced on a progressive ratio schedule decreases with continuous d-amphetamine treatment in rats. Psychopharmacology 200: 465-473.

Corwin RL, Woolverton WL, Schuster CR, Johanson CE (1987). Anorectics: effects on food intake and self-administration in rhesus monkeys. Alcohol Drug Res 7: 351-361.

Czoty P, Martelle J, Nader M (2010). Effects of chronic d-amphetamine administration on the reinforcing strength of cocaine in rhesus monkeys. Psychopharmacology 209: 375-382.

Czoty PW, Gould RW, Martelle JL, Nader MA (2011). Prolonged attenuation of the reinforcing strength of cocaine by chronic d-amphetamine in rhesus monkeys. Neuropsychopharmacology 36: $539-547$.

Czoty PW, Nader MA (2013). Effects of dopamine D2/D3 receptor ligands on food-cocaine choice in socially housed male cynomolgus monkeys. J Pharmacol Exp Ther 344: 329-338.

Grabowski J, Rhoades H, Schmitz J, Stotts A, Daruzska LA, Creson D et al (2001). Dextroamphetamine for cocainedependence treatment: a double-blind randomized clinical trial. J Clin Psychopharmacol 21: 522-526.

Grabowski J, Rhoades H, Stotts A, Cowan K, Kopecky C, Dougherty A et al (2004). Agonist-like or antagonist-like treatment for cocaine dependence with methadone for heroin dependence: two double-blind randomized clinical trials. Neuropsychopharmacology 29: 969-981.

Greenwald MK, Lundahl LH, Steinmiller CL (2010). Sustained release d-amphetamine reduces cocaine but not "speedball"seeking in buprenorphine-maintained volunteers: a test of dualagonist pharmacotherapy for cocaine/heroin polydrug abusers. Neuropsychopharmacology 35: 2624-2637.

Griffiths RR, Brady JV, Bradford LD (1979). Predicting the abuse liability of drugs with animal drug self-administration procedures: psychomotor stimulants and hallucinogens. In: Thompson T, Dews PB (eds) Advances in Behavioral Pharmacology, Vol 2. Academic Press: New York, pp 164-208.

Haney M, Spealman R (2008). Controversies in translational research: Drug self-administration. Psychopharmacology 199: 403-419.

Hernstein R, Prelec D (1992). A theory of addiction. In: Loewenstein G, Elster J (eds) Choice Over Time. Russell Sage Press: New York, pp 331-360.

Heyman GH (2009). Addiction: A disorder of choice. Harvard University Press: Cambridge.

Kalivas PW, Volkow ND (2005). The neural basis of addiction: a pathology of motivation and choice. Am J Psychiatry 162: 1403-1413.

Kerstetter KA, Ballis MA, Duffin-Lutgen S, Carr AE, Behrens AM, Kippin TE (2012). Sex differences in selecting between food and cocaine reinforcement are mediated by estrogen. Neuropsychopharmacology 37: 2605-2614.

Lenoir M, Serre F, Cantin L, Ahmed SH (2007). Intense sweetness surpasses cocaine reward. PLoS ONE 2: e698.

Mariani JJ, Pavlicova M, Bisaga A, Nunes EV, Brooks DJ, Levin FR (2012). Extended-release mixed amphetamine salts and topiramate for cocaine dependence: a randomized controlled trial. Biol Psychiatry 72: 950-956.

Nader M, Woolverton W (1991). Effects of increasing the magnitude of an alternative reinforcer on drug choice in a discrete-trials choice procedure. Psychopharmacology 105: 169-174.

Negus SS (2003). Rapid assessment of choice between cocaine and food in rhesus monkeys: Effects of environmental manipulations and treatment with d-amphetamine and flupenthixol. Neuropsychopharmacology 28: 919-931.

Negus SS (2004). Effects of the kappa opioid agonist U50,488 and the kappa opioid antagonist nor-binaltorphimine on choice between cocaine and food in rhesus monkeys. Psychopharmacology 176: 204-213.

Negus SS (2005). Effects of punishment on choice between cocaine and food in rhesus monkeys. Psychopharmacology 181: 244-252.

Negus SS, Baumann MH, Rothman RB, Mello NK, Blough BE (2009). Selective suppression of cocaine- versus food-maintained responding by monoamine releasers in rhesus monkeys: benzylpiperazine, (+)phenmetrazine, and 4-benzylpiperidine. J Pharmacol Exp Ther 329: 272-281.

Negus SS, Mello N (2003a). Effects of chronic d-amphetamine treatment on cocaine- and food-maintained responding under a progressive-ratio schedule in rhesus monkeys. Psychopharmacology 167: 324-332.

Negus SS, Mello NK (2003b). Effects of chronic d-amphetamine treatment on cocaine- and food-maintained responding under a second-order schedule in rhesus monkeys. Drug Alcohol Depend 70: $39-52$.

Negus SS, Mello NK (2004). Effects of chronic methadone treatment on cocaine- and food-maintained responding under second-order, progressive-ratio and concurrent-choice schedules in rhesus monkeys. Drug Alcohol Depend 74: 297-309.

Rothman RB, Katsnelson M, Vu N, Partilla JS, Dersch CM, Blough BE et al (2002). Interaction of the anorectic medication, phendimetrazine, and its metabolites with monoamine transporters in rat brain. Eur J Pharmacol 447: 51-57.

Rush CR, Stoops WW, Sevak RJ, Hays LR (2010). Cocaine choice in humans during d-amphetamine maintenance. J Clin Psychopharmacol 30: 152-159.

SAMHSA (2009). Treatment Episode Data Set (TEDS). Highlights2007. National Admissions to Substance Abuse Treatment Services, Vol 09-4360. Substance Abuse and Mental Health Services Administration: Rockville, MD.

SAMHSA (2012). Results from the 2011 National Survery on Drug Use and Health: Summary of National Findings, Vol 12-4713. Substance Abuse and Mental Health Services Administration: Rockville, MD. 
Spragg SDS (1940). Morphine Addiction in Chimpanzees. Comparative Psychology Monographs, Vol 79. The John Hopkins Press: Baltimore, MD, pp 1-132.

Thomsen M, Barrett AC, Negus SS, Caine SB (2013). Cocaine versus food choice procedure in rats: Environmental manipulations and effects of amphetamine. J Exp Anal Behav 99: 211-233.

Thomsen M, Fink-Jensen A, Woldbye DP, Wörtwein G, Sager TN, Holm R et al (2008). Effects of acute and chronic aripiprazole treatment on choice between cocaine self-administration and food under a concurrent schedule of reinforcement in rats. Psychopharmacology 201: 43-53.

Vocci FJ (2007). Can replacement therapy work in the treatment of cocaine dependence? And what are we replacing anyway? Addiction 102: 1888-1889.

Volkow N, Fowler J, Wang G (2004). The addicted human brain viewed in the light of imaging studies: brain circuits and treatment strategies. Neuropharmacology 47(Suppl 1): 3-13.

Supplementary Information accompanies the paper on the Neuropsychopharmacology website (http://www.nature.com/npp) 